\title{
Effect of alkan-1-ols on the structure of dopc model membrane
}

Comenius University in Bratislava, Faculty of Pharmacy, Department of Physical Chemistry, Bratislava, Slovak Republic ${ }^{2}$ Helmholtz Zentrum Berlin für Materialen und Energie, Berlin, Germany ${ }^{3}$ Frank Laboratory of Neutron Physics, Joint Institute for Nuclear Research, Dubna, Russia ${ }^{4}$ Moscow Institute of Physics and Technology, MIPT, Dolgoprudny, Russia 5 Institute for Safety Problems of Nuclear Power Plants, NAS Ukraine, Kiev, Ukraine

Received 20 June, 2017, accepted 6 July, 2017

Abstract The effect of general anaesthetics alkan-1-ols $(\mathrm{CnOH}$, where $\mathrm{n}=10,12,14,16$ and 18 is the number of carbon atoms in the molecule) on the structure of dioleoylphosphatidylcholine (DOPC) model membrane was studied by small-angle neutron scattering (SANS) and small-angle neutron diffraction (SAND). Fluid bilayers were prepared at $\mathrm{CnOH}: \mathrm{DOPC}=0.3 \mathrm{molar}$ ratio. The results of both the experiments show that bilayer thickness - a thickness parameter $d_{q}$ in the case of SANS and lamellar repeat distance D in the case of SAND - increases with increasing n. A coexistence of two lamellar phases with different D was detected by measuring the $\mathrm{C} 18 \mathrm{OH}+\mathrm{DOPC}$ oriented sample.

Keywords Model membrane-general anaesthetics-alkan-1-ols-small-angle neutron scattering-small-angle neutron diffraction-structure

\section{INTRODUCTION}

Long-chain primary alcohols (alkan-1-ol or $\mathrm{CnOH}$, where $\mathrm{n}$ is the number of carbons in aliphatic chain) display several biological activities (Fujita et al., 2008; Kubo et al., 1995; Pringle et al., 1981). The most widely known are their general anaesthetic properties (Pringle et al., 1981), which are believed to result from their interactions with biological membranes. Whilst the origin of the anaesthetic effect is discussed in terms of both their specific interactions with membrane proteins or via structural changes in lipid bilayers, neither mechanism is described adequately. Because of their amphiphilic structure, $\mathrm{CnOHs}$ penetrate into lipid bilayers of biomembranes and change their structural and dynamic properties. Some of these changes may be related to biological effects of $\mathrm{CnOHs}$. Their anaesthetic potency increases with the increase in $\mathrm{n}$ up to $n=11$ and then decreases. The compounds with $n>13$ are non-anaesthetic (Pringle et al., 1981). Such dependence on the chain length is typical for different types of biological activities of homologous series of amphiphilic molecules with long-chain substituents and is called the cut-off effect. The lipid theory of cut-off effect supposes that amphiphiles influence physical properties of lipid bilayers, for example, the bilayer thickness, and thereby induce conformational changes in transmembrane proteins, resulting in the blockage of ion channels (Balgavý \& Devínsky, 1996). In this contribution, we study the effects of $\mathrm{CnOH}(\mathrm{n}=8-18)$ on a model membrane, the dioleoylphosphatidylcholine (DOPC) bilayers, which resemble the lipid part of biological membrane. Preliminary results obtained from experiments performed by smallangle neutron diffraction (SAND) and small-angle neutron scattering (SANS) are presented.

\section{MATERIALS AND METHOD}

DOPC was purchased from Avanti Polar Lipids (Alabaster, USA), saturated and unbranched $\mathrm{CnOHs}(\mathrm{n}=10,12,14,16,18)$ were from Sigma-Aldrich (St. Louis, USA) and heavy water (99.98\% $\mathrm{D}_{2} \mathrm{O}$ ) was from Izotop (Moscow, Russia) and Chemotrade (Leipzig, Germany). Spectrosil 2000 quartz plates (75 $\mathrm{mm} \times 25$ $\mathrm{mm}$ ) were from Saint-Gobain Quartz (Saint-Gobain, France). Oriented samples were prepared for SAND measurements. Calculated amounts of DOPC and $\mathrm{CnOH}$ were co-dissolved in chloroform-methanol mixture $(3: 1 \mathrm{v} / \mathrm{v})$ in glass vials to 
achieve $\mathrm{CnOH}$ :DOPC molar ratio of 0.3 . Approximately $20 \mathrm{mg}$ of DOPC or DOPC $+\mathrm{CnOH}$ in solution were spread onto a 75 $\mathrm{cm} \times 25 \mathrm{~cm}$ quartz glass and rocked during evaporation of organic solvent (Tristram-Nagle, 2007). The remaining traces of solvent were evaporated by vacuum pump, which was done at reduced temperature $\left(-10^{\circ} \mathrm{C}\right)$ to avoid the loss of volatile $\mathrm{CnOHs}$. Before each measurement, samples were equilibrated for $24 \mathrm{~h}$ at $98 \%$ relative humidity $(\mathrm{RH})$ and temperature of 25 ${ }^{\circ} \mathrm{C}$. The samples were hydrated from a vapour phase over saturated $\mathrm{K}_{2} \mathrm{SO}_{4}$ solution at three different $\mathrm{D}_{2} \mathrm{O} / \mathrm{H}_{2} \mathrm{O}$ contrasts $\left(8 \%, 20 \%\right.$ and $50 \%$ of $\left.\mathrm{D}_{2} \mathrm{O}\right)$ to determine the phases of structure factors for the Fourier transformation. Measurements were performed using the neutron Membrane Diffractometer V1 equipped by a ${ }^{3} \mathrm{He}$ position-sensitive detector at the BER II reactor of the Helmholtz-Zentrum Berlin für Materialien und Energie. Neutron wavelength was selected at $\lambda=4.5707 \AA$.

Dispersions of unilamellar liposomes were prepared for SANS measurements. Calculated amounts of DOPC and $\mathrm{CnOH}$ were co-dissolved in chloroform-methanol mixture (3:1 v/v) in glass vials to achieve $\mathrm{CnOH}$ :DOPC molar ratio of 0.3 . Lipid was dried by a stream of gaseous nitrogen. The rest of the solvent was removed by vacuum pump. Lipid film was hydrated by $100 \%$ $\mathrm{D}_{2} \mathrm{O}$ so that the weight percentage of $\mathrm{DOPC}+\mathrm{CnOH}$ in $\mathrm{D}_{2} \mathrm{O}$ was less than $2 \%$. The dispersion of multilamellar liposomes arising in the process of agitation was then extruded through a polycarbonate membrane filter with $50-\mathrm{nm}$ diameter pores. The extrusion technique is suitable to produce unilamellar liposomes with a reasonably homogeneous diameter distribution (polydispersity of about 30\%) with a mean diameter approaching the polycarbonate membrane pore diameter (Kucerka et al., 2007). The samples of unilamellar liposomes dispersion were poured into 1-mm thick quartz cells and measured at $25.0 \pm 0.1^{\circ} \mathrm{C}$. The SANS measurements were performed at the time-of-flight spectrometer YuMO with two-detector system at IBR-2 fast pulse reactor of Frank Laboratory of Neutron Physics in Joint Institute for Nuclear Research in Dubna, Russia (Kuklin et al., 2012). The scattering curves were corrected for background (Soloviev et al., 2003).

\section{RESULTS AND DISCUSSION}

We study the interaction of homologous series of alkan-1-ols with a model membrane represented by DOPC bilayers. Fully hydrated DOPC lipids form a fluid lamellar phase at temperatures above $-17^{\circ} \mathrm{C}$ (Lewis et al., 1988). Because of their amphiphilic structure, alcohols $(\mathrm{CnOH}, \mathrm{n}=8-18)$ are intercalated in DOPC bilayer with their hydroxyl groups in the head-group region of DOPC and the hydrophobic chains parallel to the acyl chains of DOPC. It was found that DOPC $+\mathrm{CnOHs}(\mathrm{n}=8-18)$ also form homogeneous fluid bilayers without phase separation at least to $\mathrm{CnOH}$ :DOPC molar ratio of 0.4 (Kotalová et al., 2008).

In oriented samples, bilayers of $\mathrm{CnOH}+$ DOPC are aligned parallel to the flat surface of the quartz plate. Individual lipid bilayers are separated by layers of water. The number of water molecules per one DOPC molecule is only approaching the condition of full hydration because samples were hydrated in the surroundings with $98 \% \mathrm{RH}$. Such partial dehydration was, however, shown not to affect, for the most part, the bilayer structural parameters (Kucerka et al., 2009). A regular arrangement of lipid bilayers separated by interlamellar water layers causes a diffraction of neutron beam applied at small scattering angle $\theta$ (angle between the incident neutron beam and the planar surface of the bilayer). Typical diffractogram contained five to seven diffraction peaks. As an example, diffractogram obtained by $\mathrm{C} 10 \mathrm{OH}+$ DOPC oriented sample is shown in Fig. 1.

Diffraction peaks were fitted to Gaussians sitting atop of linear function describing the background. The equal distance between maxima of individual diffraction peaks confirms the lamellar arrangement. The position of peaks is given by the Bragg law,

$\mathrm{h} \lambda=2 \mathrm{D} \sin (\theta)$,

where $h$ is the order of diffraction peak, $\lambda$ is the wavelength of neutrons and $D$ is the minimum distance between periodically repeated structures. The repeat distance $D$ is the sum of the thickness of the lipid bilayer $D_{B}$ and the thickness of the water layer $D_{W}\left(D=D_{B}+D_{W}\right)$. The dependence of the repeat distance $D$ on the chain length of $\mathrm{CnOH}$ is shown in Fig. 2. It is clearly seen that shorter alcohols $(n=10-14)$ cause a decrease in D in DOPC multilayers where $\mathrm{C} 10 \mathrm{OH}$ is the most effective. Longer alcohol, $\mathrm{C} 16 \mathrm{OH}$, increases the repeat distance. Two lamellar phases with different repeat spacing were detected in the sample containing $\mathrm{C} 18 \mathrm{OH}$ (see inset to Fig. 1). $\mathrm{C} 18 \mathrm{OH}$ and DOPC probably do not mix ideally at the molar ratio of 0.3 and level of hydration used, and two phases with different $\mathrm{C} 18 \mathrm{OH}$ :DOPC molar ratio are created. Similar diffractograms were obtained after repeated preparation of $\mathrm{C} 18 \mathrm{OH}+$ DOPC oriented sample.

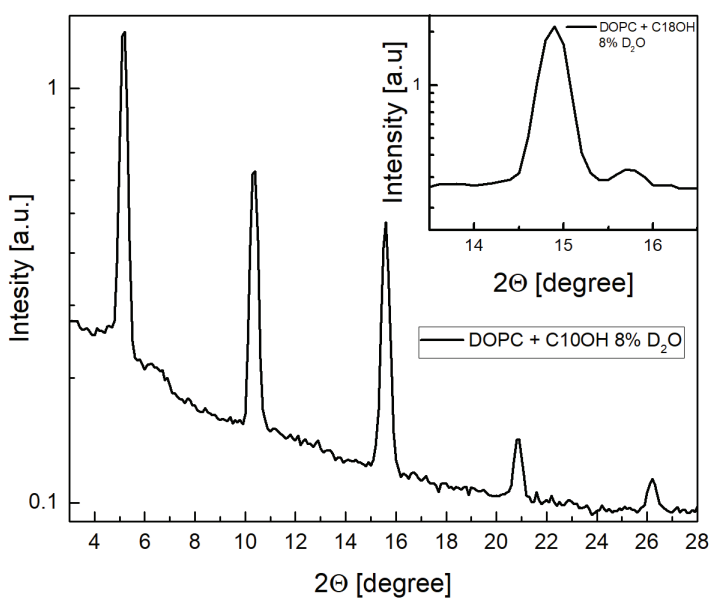

Figure1. Diffractogram of oriented $\mathrm{C10OH}+\mathrm{DOPC}$ multilayers hydrated at $98 \% \mathrm{RH}$ and $\mathrm{D} 2 \mathrm{O} / \mathrm{H} 2 \mathrm{O}$ contrast of $8 \%$. Inset - the third peak in the diffractogram of $\mathrm{DOPC}+\mathrm{C} 18 \mathrm{OH}$ multilayers documenting phase superposition. 


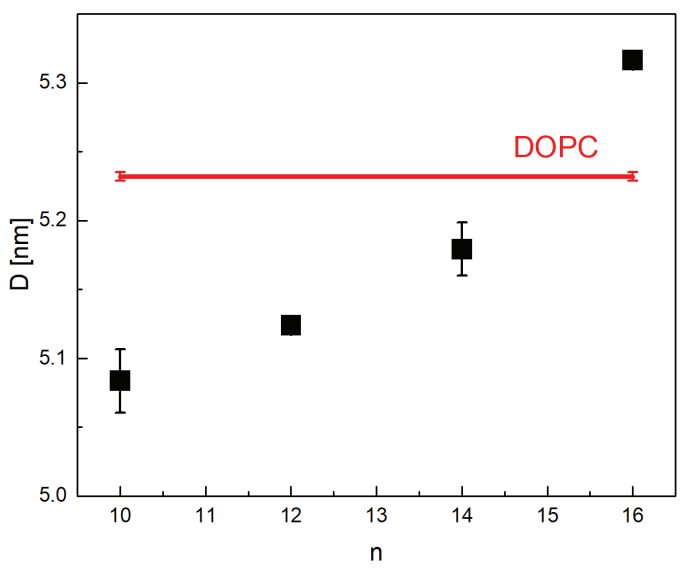

Figure2. Dependence of the repeat distance $D$ on $\mathrm{CnOH}$ alkyl length $n$. Horizontal line - DOPC as a reference.

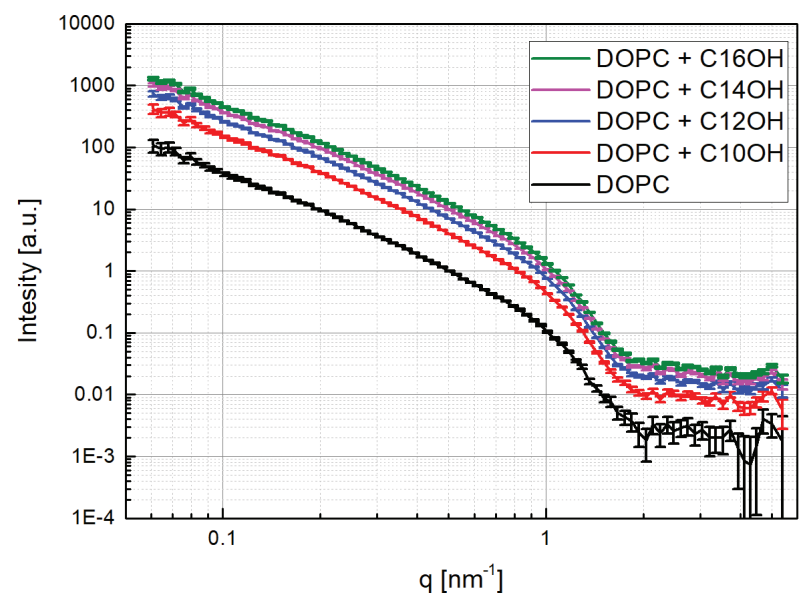

Figure3. Experimental SANS data obtained from unilamellar liposomes of $\mathrm{DOPC}+\mathrm{CnOH}$ dispersed in $\mathrm{D}_{2} \mathrm{O}$. Scattering curves are shifted vertically for clarity of presentation. From bottom to top, they correspond to DOPC bilayers and DOPC containing $\mathrm{C10OH}$, $\mathrm{C} 12 \mathrm{OH}, \mathrm{C14OH}$ and $\mathrm{C16OH}$, respectively.

Results obtained with $\mathrm{C} 18 \mathrm{OH}+\mathrm{DOPC}$, though a relative amount of the secondary phase can be estimated to be less than $5 \%$, are, therefore, excluded from further data analysis. A similar study was performed with non-oriented samples at full hydration (Petrenko et al., 2010). The increase in D with increasing $\mathrm{n}$ in $\mathrm{CnOH}: \mathrm{DOPC}$ bilayer was also observed. Because of full hydration, the values of $D$ were higher (6.03 nm for pure DOPC) and characteristic of the higher experimental error. Figure 2 shows that $\mathrm{CnOH}(n=10-16)$ are able to influence the repeat distance D of DOPC-stacked bilayers at $\mathrm{CnOH}: \mathrm{DOPC}$ molar ratio of 0.3 . On the presented level of evaluation, it is not possible to distinguish whether $D_{B}$ or $D_{w}$ or both of them are influenced by $\mathrm{CnOH}$. SAND patterns measured at various $\mathrm{D}_{2} \mathrm{O} / \mathrm{H}_{2} \mathrm{O}$ contrasts also include information regarding the internal structure of the lipid bilayer. After the correction of Bragg peak intensities for incident flux, sample absorption and Lorentz correction, form factor phases can be determined through the isotopic replacement of $\mathrm{H}_{2} \mathrm{O}$ for $\mathrm{D}_{2} \mathrm{O}$. Scattering length density profile of the bilayer can then be acquired using scattering form factors through their Fourier transformation. This more advanced evaluation described, for example, in Kucerka et al., 2009 will be presented in future.

Experimental SANS data are dependencies of scattered intensity I on the scattering vector modulus $q=4 \pi \sin (\theta) / \lambda$. Scattering curves for DOPC and $\mathrm{CnOH}+$ DOPC are shown in Fig. 3. It was experimentally shown (see, e.g. Kučerka et al., 2003, for citations) that the interparticle interaction between unilamellar liposomes is negligible at the lipid concentrations and liposome sizes used. When the bilayer thickness is small compared to liposome radii, neutron scattering on liposomes can be approximated by the scattering on randomly oriented planar sheets having the same thickness $d_{g}$. The Kratky-Porod approximation can be used in some range of q:

$I(q)=A q^{-2} \exp \left(-q^{2} R_{g}{ }^{2}\right)$

where $A$ is a scaling constant and $R_{g}$ is the radius of gyration. The thickness of two-dimensional planar sheet $d_{g}\left(d_{g}{ }^{2}=12 R_{g}{ }^{2}\right)$ can be determined using the Kratky-Porod plot $\left(\operatorname{Ln}\left(\mid q^{2}\right)=f\left(q^{2}\right)\right)$. We found that $d_{g}=3.93 \pm 0.08 \mathrm{~nm}$ for DOPC without $\mathrm{CnOH}$ similar to $3.78 \pm 0.02 \mathrm{~nm}$ (Kučerka et al., 2003), $3.90 \pm 0.08 \mathrm{~nm}$ (Uhríková et al., 2000), $3.92 \pm 0.06$ nm (Uhríková et al., 2003) and $3.91 \pm 0.02 \mathrm{~nm}$ (Uhríková et al., 2001).

It was shown that bilayer thickness parameter $d_{g}$ is linearly correlated with the transbilayer phosphate-phosphate distance in unilamellar diacylphosphatidylcholine liposomes (Balgavý et al., 2001). This indicates that changes in thickness parameter $d_{g}$ can reflect rather well changes in the bilayer thickness. Obviously, the values of $\mathrm{d}_{\mathrm{g}}$ are smaller than the steric thickness (e.g. $4.97 \pm 0.07 \mathrm{~nm}$ for pure DOPC; Kučerka et al., 2007) obtained when taking into account the internal structure of the bilayer with some water molecules penetrating into the polar region of the bilayer. Figure 4 shows that the bilayer thickness parameter $d_{g}$ increases with increasing $n$ reaching the $d_{g}$ value of pure DOPC bilayer at $\mathrm{C} 16 \mathrm{OH}$. However, the decrease in $\mathrm{d}_{\mathrm{g}}$ caused by the shortest alcohol $\mathrm{C} 10 \mathrm{OH}$ is only mild, around $0.1 \mathrm{~nm}$. Unfortunately, the experimental error of $\mathrm{d}_{\mathrm{g}}$ is quite large. We suppose that more precise values of the bilayer thickness will be obtained by fitting of the scattering curve in a broader range of $q$ in advanced evaluation using a more realistic model of SANS on unilamellar vesicles as shown in our previous papers (e.g. Gallová et al., 2011).

Similar effect of $\mathrm{CnOH}$ on the lipid bilayer thickness as shown in Fig. 4 was observed in Klacsová et al. (2011), wherein the steric thickness of the mixed DOPC-DOPS (dioleoylphosphatidylserine) bilayer (DOPC:DOPS molar ratio of 25 ) was studied by SANS. The decrease in the bilayer thickness caused by short alcohols was explained by the mismatch between the chain length of $\mathrm{CnOH}$ and lipid- the insertion of shorter alcohol molecule into a lipid bilayer creates a free space under its terminal methyl group, which is filled-in 


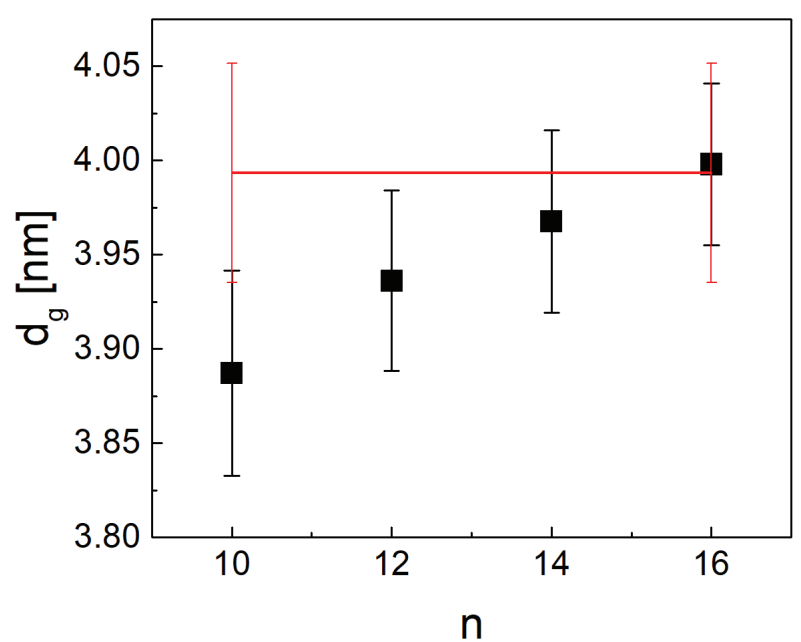

Figure4. Dependence of the bilayer thickness parameter $d g$ on $\mathrm{CnOH}$ alkyl length $n$. Horizontal line - DOPC as a reference. with neighbouring lipid acyl chains. This causes a decrease in the bilayer thickness. Such defects become smaller when longer-chain alcohol is intercalated in the same bilayer.

In conclusion, the preliminary results of SAND experiments on aligned planar bilayers with limited hydration show that shorter alcohols $(\mathrm{CnOH}, \mathrm{n}=10-14)$ decrease the repeat distance, whilst $\mathrm{C} 16 \mathrm{OH}$ causes its increase. It was determined using SANS that the parameter of the bilayer thickness $d_{g}$ increases with increasing $n$ reaching the $d_{g}$ value of pure DOPC bilayer at $\mathrm{C} 16 \mathrm{OH}$.

\section{ACKNOWLEDGEMENT}

This work was supported by VEGA grants 1/0916/16, 1/0228/17, Dubna JINR 04-4-1121-2015/2017 project and European Commission under the 7th Framework Programme through the 'Research Infrastructure' action of the 'Capacities' Programme, NMI3-II Grant number 283883. We thank the HZB and JINR for providing the neutron beam time with the accepted proposals.

\section{References}

[1] BalgavýP,DevínskyF.Cut-offeffectsin biologicalactivities of surfactants. Adv Colloid Interfac. 1996;66:23-63.

[2] BalgavýP,DubničkováM,KučerkaN,KiselevMA,Yaradaikin SP, Uhríková D. Bilayer thickness and lipid interface area in unilamellar extruded 1,2-diacylphosphatidylcholine liposomes: A small-angle neutron scattering study. Biochim Biophys Acta. 2001;1512:40-52.

[3] Fujita Kl, Fujita T, Kubo I. Antifungal activity of alkanols against Zygosaccharomyces bailii and their effects on fungal plasma membrane. Phytother Res. 2008;22:1349-55.

[4] Gallová J, Uhríková D, Kučerka N, Svorková M, Funari SS, Murugova TN, Balgavý P. Influence of cholesterol and $\beta$-sitosterol on the structure of EYPC bilayers. J Membr Biol. 2011;243:1.

[5] Hope MJ, Bally MB, Mayer LD, Janoff AS, Cullis PR. Generationofmultilamellarandunilamellarphospholipid vesicles. Chem Phys Lipids. 1986;40:89-107.

[6] Hope MJ, Bally MB, Webb G, Cullis PR. Production of large unilamellar vesicles by a rapid extrusion procedure. Characterization of size distribution, trapped volume and ability to maintain a membrane potential. Biochim Biophys Acta. 1985;812:55-65.

[7] Klacsová M, Bulacu M, Kučerka N, Uhríková D, Teixeira J, Marrink SJ, Balgavý P. The effect of aliphatic alcohols on fluid bilayers in unilamellar DOPC vesicles--a smallangle neutron scattering and molecular dynamics study. Biochim Biophys Acta. 2011;1808:2136-46.

[8] Kotalová M, Uhríková D, Funari SS, Balgavý P. Influence of long-chain alcohols on structural parameters of DOPC bilayers. In: HASYLAB Annual Report 2007. 2008; Hamburg.

[9] Kubo I, Muroi H, Kubo A. Structural functions of antimicrobial long-chain alcohols and phenols. Bioorg Med Chem. 1995;3:873-880.
[10] Kucerka N, Nieh M, Pencer J, Sachs J, Katsaras J. What determines the thickness of a biological membrane. Gen Physiol Biophys. 2009;28:117-125.

[11] Kučerka N, Uhríková D, Teixeira J, Balgavý P. Lipid Bilayer Thickness In Extruded Liposomes Prepared From 1 , 2-Diacylphosphatidylcholines With Monounsaturated Acyl Chains: A Small-Angle Neutron Scattering Study. Acta Fac Pharm Univ Comen. 2003;50:78-89.

[12] Kučerka N, Pencer J, Nieh MP, Katsaras J. Influence of cholesterol on the bilayerproperties of monounsaturated phosphatidylcholine unilamellar vesicles. Eur Phys J E. 2007;23:247-254.

[13] Lewis RNAH, Sykes BD, McElhaney RN. Thermotropic phase behavior of model membranes composed of phosphatidylcholines containing cis-monounsaturated acyl chain homologs of oleic acid: differential scanning calorimetric and phosphorus-31 NMR spectroscopic studies. Biochemistry. 1988;27:880-887

[14] Mayer LD, Hope MJ, Cullis PR. Vesicles of variable sizes produced by a rapid extrusion procedure. Biochim Biophys Acta. 1986;858:161-168.

[15] Olson F, Hunt CA, Szoka FC, Vail WJ, Papahadjopoulos D. Preparation of liposomes of defined size distribution by extrusion through polycarbonate membranes. Biochim Biophys Acta. 1979;557:9-23.

[16] Petrenko VI, Klacsova M, Beskrovnyy Al, Uhrikova D, Balgavy P. Interaction of long-chain $n$-alcohols with fluid DOPC bilayers: a neutron diffraction study. Gen Physiol Biophys. 2010;29:355-61.

[17] Pringle MJ, Brown K B, Miller KW. Can the lipid theories of anesthesia account for the cutoff in anesthetic potency in homologous series of alcohols? Mol Pharmacol. 1981;19:49-55. 
[18] Soloviev AG, Solovieva TM, Stadnik AV, Islamov AK, Kuklin AI. SAS. Program for primary processing of smallangle scattering spectra. Version 2.4. Description and user guide. Soobshch Oblcdprime ed Inst Yadernykh Issled Dubna. 2003;P10-2003-86.

[19] Tristram-NagleSA.Preparation of oriented, fully hydrated lipid samples for structure determination using X-ray scattering. Methods Mol Biol. 2007;400:63-75.

[20] Uhríková D, Balgavý P, Kučerka N, Islamov A, Gordeliy V, Kuklin A. Small-angle neutron scattering study of the $\mathrm{n}$-decane effect on the bilayer thickness in extruded unilamellar dioleoylphosphatidylcholine liposomes. Biophys Chem. 2000;88:165-170.

[21] Uhríková D, Kučerka N, Islamov A, Gordeliy V, Balgavý P. Small-angle neutron scattering study of N-dodecyl$\mathrm{N}, \mathrm{N}$-dimethylamine-N-oxide induced solubilization of dioleoylphosphatidylcholine bilayers in liposomes. Gen. Physiol. Biophys. 2001;20:183-189.

[22] Uhríková D, Kučerka N, Islamov A, Kuklin A, Gordeliy V, Balgavý P. Small-angle neutron scattering study of the lipid bilayer thickness in unilamellar dioleoylphosphatidylcholine vesicles prepared by the cholate dilution method: n-decane effect. Biochim Biophys Acta. 2003;1611:31-34. 